\title{
A Plasma Inhibitor of the Renin-Antirenin Reaction and the In Vitro Generation of Angiotensin I
}

\author{
C. P. Lucas, W. K. Waldhausl, E. L. Cohen, F. G. Berlinger, \\ W. J. McDonald, and R. S. Sider
}

In the course of studies designed to develop a radioimmunoassay system for the detection of renin, we have identified in human plasma a potent inhibitor that interferes with the renin-antirenin reaction. Utilizing gel filtration, this renin-antirenin inhibitory activity was found to have the same molecular size as renin substrate.

However, it could be separated from renin substrate by ion-exchange chromatography. When fractions containing this activity were tested in an in vitro system containing renin and renin substrate, they were found to inhibit the generation of angiotensin I.

W HEN PLASMA is incubated at $37^{\circ} \mathrm{C}$, the reaction that takes place between the enzyme renin and its substrate, in the presence of certain added inhibitors to angiotensinanses and converting enzyme, results in the generation of angiotensin I (AI). The rate of this reaction can be determined by either bioassay or radioimmunoassay of $\mathrm{AI}$, and this function is referred to as plasma renin activity (PRA). It is generally recognized that various factors besides renin, such as inhibitors, ${ }^{1-3}$ activators, or the concentration of renin substrate ${ }^{4-7}$ influence the PRA. Thus the correlations between renin concentration (by indirect methods) and PRA in plasma of normal people and in plasma of women on oral contraceptives do not run exactly parallel. ${ }^{7}$

The theoretical advantages in having a method for the direct measurement of renin in blood are thus obvious. The recent availability of a highly purified preparation of human renin ${ }^{8}$ and potent antisera to it encouraged us to explore the feasibility of developing a radioimmunoassay for renin. In the course of our investigation we labeled human renin with iodine-131 without detectable "damage." By employing a double-antibody technique to separate free ${ }^{131}$ I-renin from that bound to antibody, we found that we could detect both purified renin in buffer and endogenous renin in human plasma. The most striking observation made was the detection of a plasma inhibitor to the renin-antirenin reaction. This inhibitor later proved to have the same molecular size as renin substrate, but could be separated from the latter by ion-exchange chromatography. When tested in an in vitro system, in the presence of exogenous renin and renin

From the Division of Endocrinology and Metabolism and the Metabolism Research Unit, Department of Internal Medicine, University of Michigan Medical School, Ann Arbor, Mich.

Received for publication A ugust 19,1974.

Supported in part by a grant from the Michigan Heart Association, by USPHS grant AM-10257. by the National Institute of Arthritis and Metabolic Diseases, and by grant RR-42 from the General Clinical Research Centers Program of the Division of Research Resources, National Institutes of Health.

Reprint requests should be addressed to C.P. Lucas, M.D., Department of Internal Medicine, Wayne State University Medical School, Hutzel Hospital Medical Unit, 432 East Hancock, Detroit, Mich. $4820 l$.

(c) 1975 by Grune \& Stratton, Inc. 
substrate, this renin-antirenin inhibiting fraction was found to decrease the generation of angiotensin $I$.

\section{MATERIALS AND METHODS}

Sephadex G-200 was purchased from Pharmacia Fine Chemicals, Uppsala, Sweden, and DEAE cellulose from Sigma Chemical Co., St. Louis, Mo. Bovine serum albumin (Fraction V) was obtained from Armour Pharmaceutical Co., Chicago, and $\mathrm{Na}^{131}$ I from Union Carbide Corp., New York. Pooled plasma used for the isolation of renin substrate was obtained from Michigan State Laboratories, Lansing, Mich. (The combined plasma of 600 normotensive donors was used to form the pool.)

Preparation of antirenin and radioiodinated renin. Purified human renin ${ }^{8}$ was used both for the production of antirenin and for labeling with radioactive iodine. Antirenin was produced in New Zealand rabbits injected subcutaneously at biweekly intervals with $0.5 \mathrm{mg}$ of purified human renin mixed with complete Freund's adjuvant. Antibody titers were estimated by determining the dilutions of antiserum needed to inhibit the renin activity of normal human plasma. Purified human renin $(1.5 \mu \mathrm{g})$ with a potency of 5 to 13 Goldblatt units per milligram was labeled with $1 \mathrm{mCi}$ of $\mathrm{Na}^{131} \mathrm{I}$ by either the method of Hunter and Greenwood ${ }^{9}$ or the method of McFarlane. ${ }^{10}$ Radioiodinated renin, with a specific activity of $100-200 \mathrm{mCi} / \mathrm{mg}$, was purified by polyacrylamide disc-gel electrophoresis, using $10.5 \%$ acrylamide ( $\mathrm{pH} 8.9$ ).

Collection and handling of blood specimens. Blood from normal subjects and from hypertensive patients was collected in ammonium EDTA (final concentration $3 \mathrm{mM}$ ) and was chilled immediately in ice. Plasma was separated by centrifugation and stored at $-20^{\circ} \mathrm{C}$ until the time of assay.

Renin radioimmunoassay. For this radioimmunoassay, all reactions were run at $4^{\circ} \mathrm{C}$. Dilutions of reagents were made with borate buffer $\left(8.25 \mathrm{~g}\right.$ boric acid, $2.7 \mathrm{~g} \mathrm{NaOH}, 1.86 \mathrm{~g} \mathrm{Na}_{2}$ EDTA, $0.1 \mathrm{~g}$ merthiolate in 1 liter of water, adjusted to $\mathrm{pH} 8.0$ with $\mathrm{HCl}$ ) containing $1 \%$ bovine serum albumin. The incubation mixture contained $0.1 \mathrm{ml}$ of radioiodinated renin (approximately 10,000 c.p.m.), $0.1 \mathrm{ml}$ of a 1:10,000 dilution of antirenin, 0.05 to $0.2 \mathrm{ml}$ of plasma to be assayed or $0.1 \mathrm{ml}$ of purified renin standard ( 75 to $5,000 \mathrm{pg}$ per tube), and 0.3 to $0.45 \mathrm{ml}$ of borate buffer, to bring the initial reaction volume to $0.7 \mathrm{ml}$. Free ${ }^{131} \mathrm{I}$-renin was separated from antibody-bound ${ }^{131} \mathrm{I}$-renin after $48-96 \mathrm{hr}$ incubation, by double antibody precipitation of soluble renin-antirenin complex. ${ }^{11}$ Radioactivity was measured in a Packard Autogamma counter. Values for renin determined by radioimmunoassay are expressed as nanograms per milliliter.

Renin activity assay. All plasmas assayed in the renin radioimmunoassay were also assayed for renin activity by the rat bioassay, using a modification of the Boucher method. ${ }^{12}$ Results are expressed as nanogram equivalents of angiotensin II generated per $100 \mathrm{ml}$ of blood during a 3-hr incubation at $37^{\circ} \mathrm{C}$.

Tests for damage to radioiodinated renin. Equal volumes of radioiodinated renin (100,000 c.p.m./ $0.1 \mathrm{ml}$ ) and human plasma were incubated at $4^{\circ} \mathrm{C}$ for $24,48,96,120$, and $144 \mathrm{hr}$. This mixture was then run in a poly acrylamide disc-gel electrophoresis system ( $10.5 \%$ acrylamide, $\mathrm{pH} 8.9$ ).

Complement fixation. Inhibition by human serum of the renin-antirenin reaction was studied by complement fixation. ${ }^{13}$

Isolation form human plasma of both an inhibitor to the renin-antirenin reaction and an inhibitor to the in vitro generation of angiotensin $I$. Pooled human plasma was fractionated at $4^{\circ} \mathrm{C}$ by (1) Sephadex G-200 chromatography, employing a $2.5-\times 100-\mathrm{cm}$ column, eluted with a $0.075-\mathrm{M}$ phosphate buffer, pH 7.5; and (2) by DEAE cellulose chromatography, employing a 5- $\times 40-\mathrm{cm}$ column, eluted with an ascending salt gradient (from zero to $0.25-\mathrm{M} \mathrm{NaCl}$ ) in $0.01-\mathrm{M}$ acetate buffer, $\mathrm{pH} 5.5$. Fractions were collected and assayed for substrate concentration and renin-antirenin inhibitory activity. Certain fractions were then pooled, concentrated, and tested for (1) inhibition to the generation of angiotensin I by renin and (2) angiotensinase activity.

1. Assay for plasma inhibitor to the renin-antirenin reaction: It was found quite early in the development of the radioimmunoassay for renin that low-renin-activity plasma (or anephric plasma) could inhibit the binding of ${ }^{131} \mathrm{I}$-renin to antirenin (see Fig. 1). Therefore, a particular low-reninactivity plasma was chosen as a laboratory standard against which inhibitory activity to the reninantirenin reaction could be measured. Dilutions of this plasma were used in place of renin standards in the renin radioimmunoassay described above. This standard curve was used to estimate inhibitory activity in fractions obtained from chromatography. This inhibitory activity was expressed as microliter equivalents of this standard plasma. 
Fig. 1. Standard curve (with circles) of radioimmunoassay. Bind without renin $\left(B_{0}\right)$ was $30 \%-40 \%$ of total counts. Aenin standerd was varied from 0.075 to $5.0 \mathrm{ng} / \mathrm{tube}$. The second curve (with $x^{\prime}$ 's) shows the effect on binding of adding 50-400 $\mu$ l of low-reninactivity human plasma (PRA undetectable).

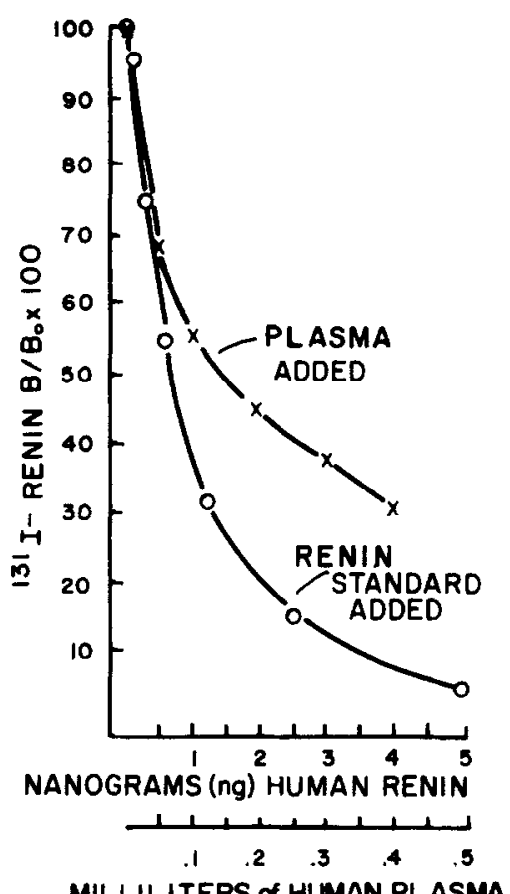

MILLILITERS Of HUMAN PLASMA

2. Assay for inhibitor to the enzymatic action of renin: Fractions obtained from DEAE cellulose and Sephadex G-200 chromatography were combined (pools A, B, C, D, C 1 , and $\mathrm{C}_{2}$ as shown in Figs. 4 and 6) and concentrated (Diaflo ultrafiltration apparatus), and then dialyzed against 0.1-M acetate buffer ( $\mathrm{pH} 5.6$ ). Assay for inhibitory activity (enzymatic) was made by adding $50 \mu \mathrm{l}$ of the concentrated pool to $50 \mu$ l of plasma ( $\mathrm{pH} 5.6$ ) serving as renin substrate, $10 \mu \mathrm{l}$ of 0.3 -M disodium ethylenediaminetetracetate, $2 \mu \mathrm{l}$ of diisopropylfuorophosphate (DFP) solution (1:3 dilution of DFP with isopropanol), and $10 \mu \mathrm{l}$ of human renin (see Fig. 5 and Table 4 for other details). In control assays 50 $\mu \mathrm{l}$ of $0.1-\mathrm{M}$ acetate buffer (pI 5.6) containing $1 \%$ bovine serum albumin was substituted for pooled fractions. These mixtures were incubated for $30 \mathrm{~min}$ at $37^{\circ} \mathrm{C}$, and the angiotension I generated was measured by radioimmunoassay. ${ }^{14}$ Pooled fractions found to diminish the amount of angiotensin $\mathrm{I}$ were tested for angiotensinase activity by substituting $10 \mu \mathrm{l}$ of angiotensin I for the $10 \mu \mathrm{l}$ of renin in the above mixtures prior to incubation (final concentration approximately $10 \mathrm{ng} \mathrm{AI} / \mathrm{ml}$, see Table 3 ).

3. Assay for substrate concentration: Eluates from DEAE cellulose and Sephadex G-200 chromatography were assayed for substrate concentration by incubating $50 \mu \mathrm{l}$ of eluate with $5 \mu \mathrm{l}$ of 0.03-M disodium EDTA, $2 \mu \mathrm{l}$ of DFP solution, and $6 \mu \mathrm{l}$ of an angiotensinase-free preparation of human renin (equivalent to $10^{-2} \mathrm{Goldblatt}$ units) for $1 \mathrm{hr}$ at $37^{\circ} \mathrm{C}$. Substrate activity was estimated by measuring the amount of generated angiotensin I employing a radioimmunoassay. ${ }^{15}$

\section{RESULTS}

\section{Renin Radioimmunoassay: Correlation with Bioassay}

A standard curve for the renin radioimmunoassay is shown in Fig. 1 (mean curve of 20 assays). The results comparing immunoreactive renin (IRR) with PRA, as performed on a total of 448 human plasma specimens in 20 separate assays, are shown in Table 1. The correlation between IRR and PRA is significant for three groups of plasmas in which the average PRA of the group is high (assays 25, 34, and 117). In assays where the average PRA is lower, correlations are always positive but often not statistically significant. 
Table 1. Correlation between Plasmo Renin Activity (PRA) and Immunoreactive Renin (IRR)

\begin{tabular}{|c|c|c|c|c|c|}
\hline $\begin{array}{l}\text { Assay } \\
\text { Number }\end{array}$ & $N$ & $\begin{array}{c}\text { Average } \\
\text { PRA } \\
\mathrm{ng} \mathrm{All} / 100 \\
\mathrm{ml} / 3 \mathrm{hr}\end{array}$ & $\begin{array}{c}\text { Average } \\
\mid \mathrm{RR} \\
\mathrm{ng} / \mathrm{mI}\end{array}$ & $r$ & $\begin{array}{l}\text { Statistical } \\
\text { Significance }\end{array}$ \\
\hline 25 & 8 & 2925 & 16.3 & +0.878 & $\mathrm{~S}$ \\
\hline 34 & 34 & 2412 & 12.3 & +0.657 & $\mathbf{S}$ \\
\hline 38 & 28 & 614 & 4.1 & +0.090 & NS \\
\hline 39 & 21 & 809 & 3.85 & +0.512 & $\mathbf{S}$ \\
\hline 41 & 35 & 493 & 4.65 & +0.020 & NS \\
\hline 42 & 22 & 711 & 4.35 & +0.471 & $\mathbf{S}$ \\
\hline 43 & 35 & 490 & 5.74 & +0.216 & NS \\
\hline 43a & 21 & 801 & 5.53 & +0.203 & NS \\
\hline 44 & 17 & 681 & 5.44 & +0.267 & NS \\
\hline 45 & 15 & 132 & 2.01 & +0.337 & NS \\
\hline 46 & 23 & 565 & 4.25 & +0.636 & $\mathbf{S}$ \\
\hline 47 & 24 & 577 & 3.66 & +0.190 & NS \\
\hline 50 & 36 & 615 & 2.55 & +0.188 & NS \\
\hline 83 & 20 & 493 & 2.3 & +0.412 & NS \\
\hline 95 & 20 & 494 & 12.5 & +0.530 & S \\
\hline 96 & 20 & 494 & 8.44 & +0.130 & NS \\
\hline 106 & 20 & 524 & 0.9 & +0.354 & NS \\
\hline 108 & 20 & 524 & 0.91 & +0.316 & NS \\
\hline 110 & 20 & 524 & 1.87 & +0.168 & NS \\
\hline 117 & 20 & 1697 & 3.67 & +0.588 & $\mathbf{S}$ \\
\hline
\end{tabular}

$N=$ number of samples in assay.

$r=$ coefficient of correlation.

NS indicates that the correlation was not statistically significant at the $5 \%$ level of confidence. while $\mathrm{S}$ indicates statistical significance at the $5 \%$ level or beyond.

\section{Inhibition by Plasma to the Renin-Antirenin Reaction}

Not due to renin content of plasma. Figure 1 shows inhibition to binding of ${ }^{131}$ I-renin to antirenin, induced (a) by added renin standard and (b) by plasma that contains very low renin activity (undetectable by bioassay). As little as $50 \mu \mathrm{l}$ of this plasma significantly decreased binding of ${ }^{131}$ I-renin to antirenin. With increasing amounts of plasma, the curve becomes similar but not identical to the standard curve of the radioimmunoassay. Since the amount of renin estimated in the low-renin-activity plasma is probably too low to account for this observed degree of inhibition, and since a similar effect was produced by plasma obtained from anephric individuals, it seems probable that this inhibitory activity is not due to renal renin.

Failure to find significant incubation damage to radioiodinated renin. No detectable change was observed in the polyacrylamide electrophoretic pattern of ${ }^{131} \mathrm{I}$-renin that had been preincubated with human plasma at $4^{\circ} \mathrm{C}$ for periods up to 6 days (see Fig. 2). Furthermore, ${ }^{131} \mathrm{I}$-renin that was eluted from the polyacrylamide did not exhibit any decline in binding due to this incubation, upon the addition of excess antirenin (70\% bind vs. $59 \%$ for control, using double-antibody technique).

Inhibition of complement fixation. Highly purified renin and various titers of antirenin were incubated overnight with and without human serum, and these reactions were tested for complement fixation (Table 2 ). Renin and antirenin in- 
Fig. 2. ${ }^{131}$-renin profile tollowing fractionation by polyecrylamide disc-gel elec-

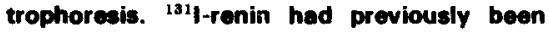
incubated with human plasma or buffer las a control) for 6 days at $4^{\circ} \mathrm{C}$. Gels were cut in $1-\mathrm{mm}$ slices, and the radioactivity of each slice was measured.

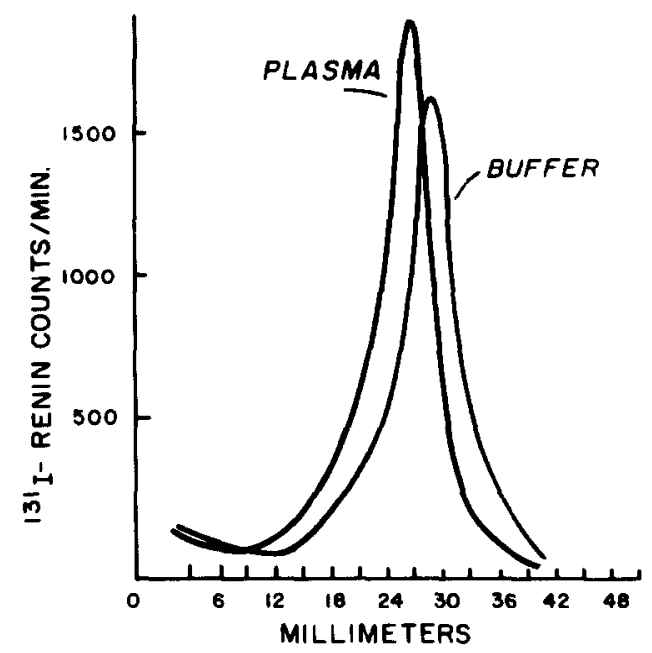

Table 2. Inhibition of Complement Fixation " by Normal Human Serum

\begin{tabular}{|c|c|c|c|c|c|c|c|c|c|c|c|c|c|}
\hline Antigen & Antibody:Dilution & $1: 2$ & $1: 4$ & $1: 8$ & $1: 16$ & $1: 32$ & $1: 64$ & $1: 128$ & $1: 256$ & $1: 512$ & $1: 1024$ & $1: 2048$ & $1: 4096$ \\
\hline Renin & Antirenin with & & & & & & & & & & & & \\
\hline $\begin{array}{l}0.8 \mu \mathrm{g} / \mathrm{ml} \\
\text { Renin }\end{array}$ & $\begin{array}{l}\text { buffer } \\
\text { Antirenin with }\end{array}$ & 4 & 4 & 4 & 4 & 4 & 3 & 3 & 3 & 3 & 3 & 2 & 0 \\
\hline $0.8 \mu \mathrm{g} / \mathrm{ml}$ & serum diluted $1: 5$ & 4 & 3 & 2 & 0 & 0 & 0 & 0 & 0 & 0 & 0 & 0 & 0 \\
\hline $\begin{array}{l}\text { Renin } \\
0.8 \mu \mathrm{g} / \mathrm{ml}\end{array}$ & $\begin{array}{l}\text { Antirenin with } \\
\text { serum diluted } 1: 50\end{array}$ & 4 & 4 & 3 & 0 & 0 & 0 & 0 & 0 & 0 & 0 & 0 & 0 \\
\hline
\end{tabular}

- Complement fixation graded 0 to 4. Presence of serum associated with decrease in fixation of complement.

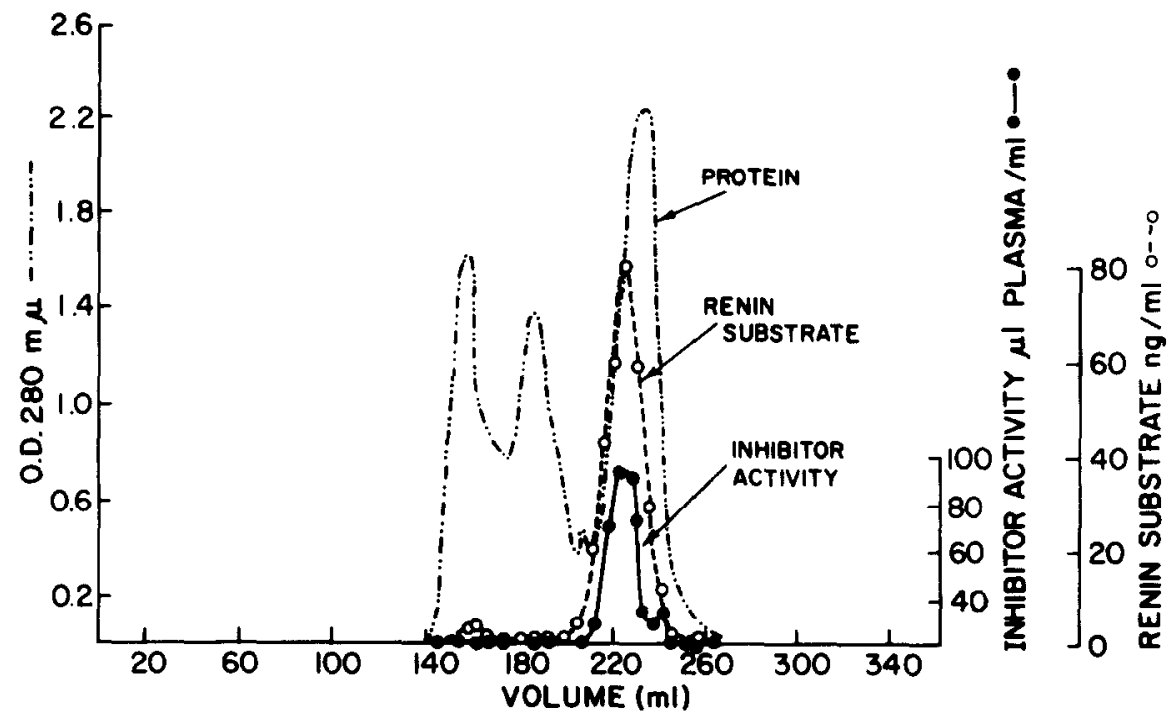

Fig. 3. Profile of renin substrate activity and renin-antirenin inhibitory activity in fractions ob tained from Sephadex G-200 column chromatography of pooled human plasma. 
cubated with buffer alone resulted in fixation of complement. On the other hand, significant inhibition of complement fixation occurred when this same reaction was studied in the presence of human serum in dilutions of 1:5 and 1:50.

\section{Isolation of Inhibitor}

When pooled plasma from normotensive donors was fractionated by Sephadex G-200 column chromatography, renin-antirenin inhibitory activity eluted as a distinct peak (Fig. 3). As determined by its elution volume, the molecular weight of this peak was about 75,000 (compared with renin, MW 40,000). Furthermore, the peak of the renin-antirenin inhibitory activity correlated very closely with the peak of substrate activity. However, when this same pooled plasma was fractionated by DEAE cellulose chromatography (Fig. 4), renin-antirenin inhibitory activity eluted over a wider range. The largest peak preceded the substrate fractions, while a minor band correlated with the appearance of the substrate peak. Beyond that point renin-antirenin inhibitory activity was undetectable, while substrate activity continued to elute.

The fractions obtained from DEAE cellulose chromatography were combined into four pools (see Fig. 4), concentrated 60-fold, and tested for inhibition to the

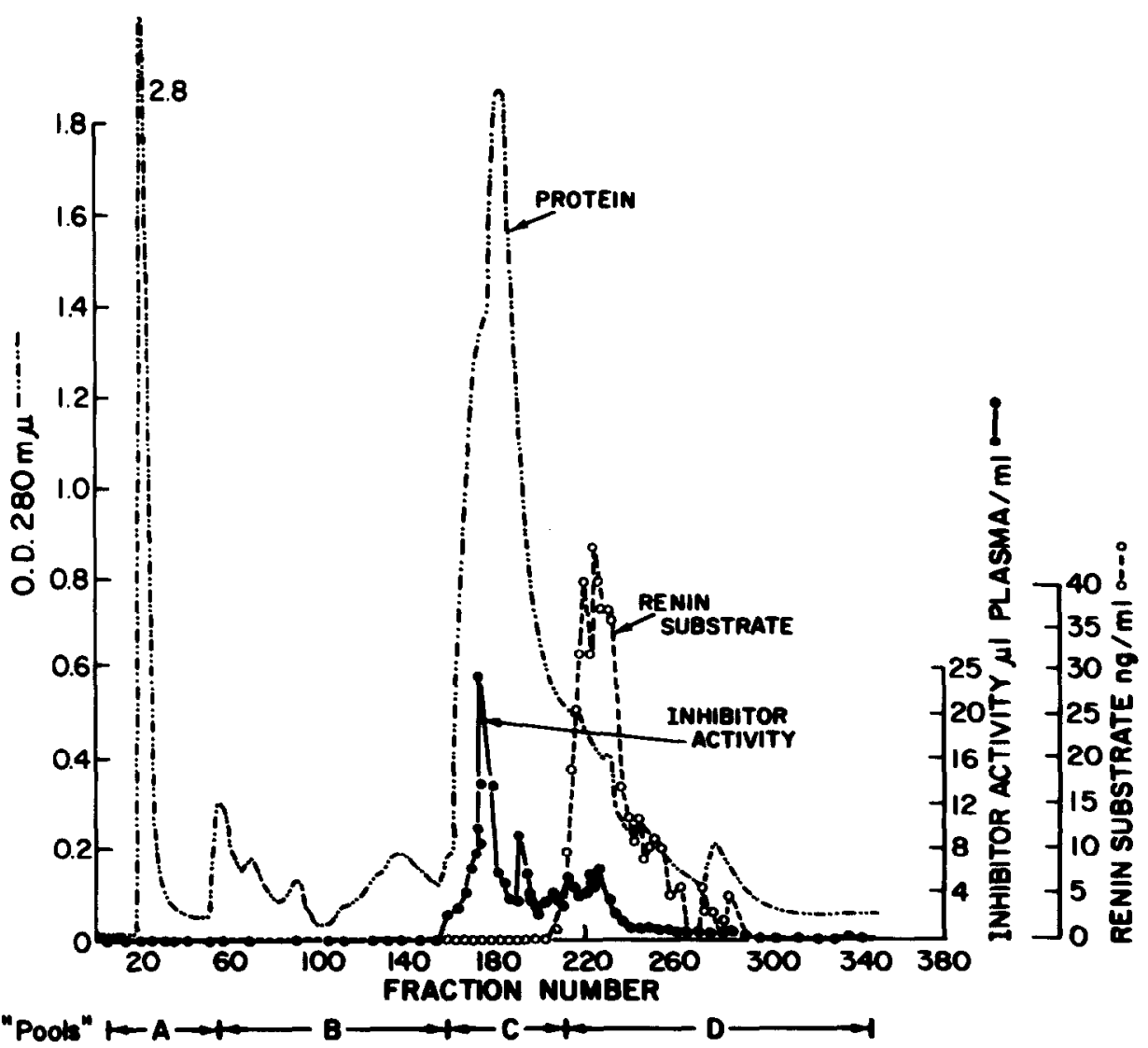

Fig. 4. Profile of renin substrate activity and renin-antirenin inhibitory activity in fractions obtained from DEAE cellulose column chromatography of pooled human plasma. 
Fig. 5. Meesurement of inhibitory activity to the enzymatic action of renin in pools obtained from DEAE cellulose column chromatography (see Fig. 4, pools A-D). Experiments were carried out as described in Methods, section 2. Low. renin-activity plasma was used as a substrate source (S). Human renin was diluted serially with buffer, and $10 \mu \mathrm{l}$ of the various dilutions were added to each sample, giving the range of renin concentration observed above.

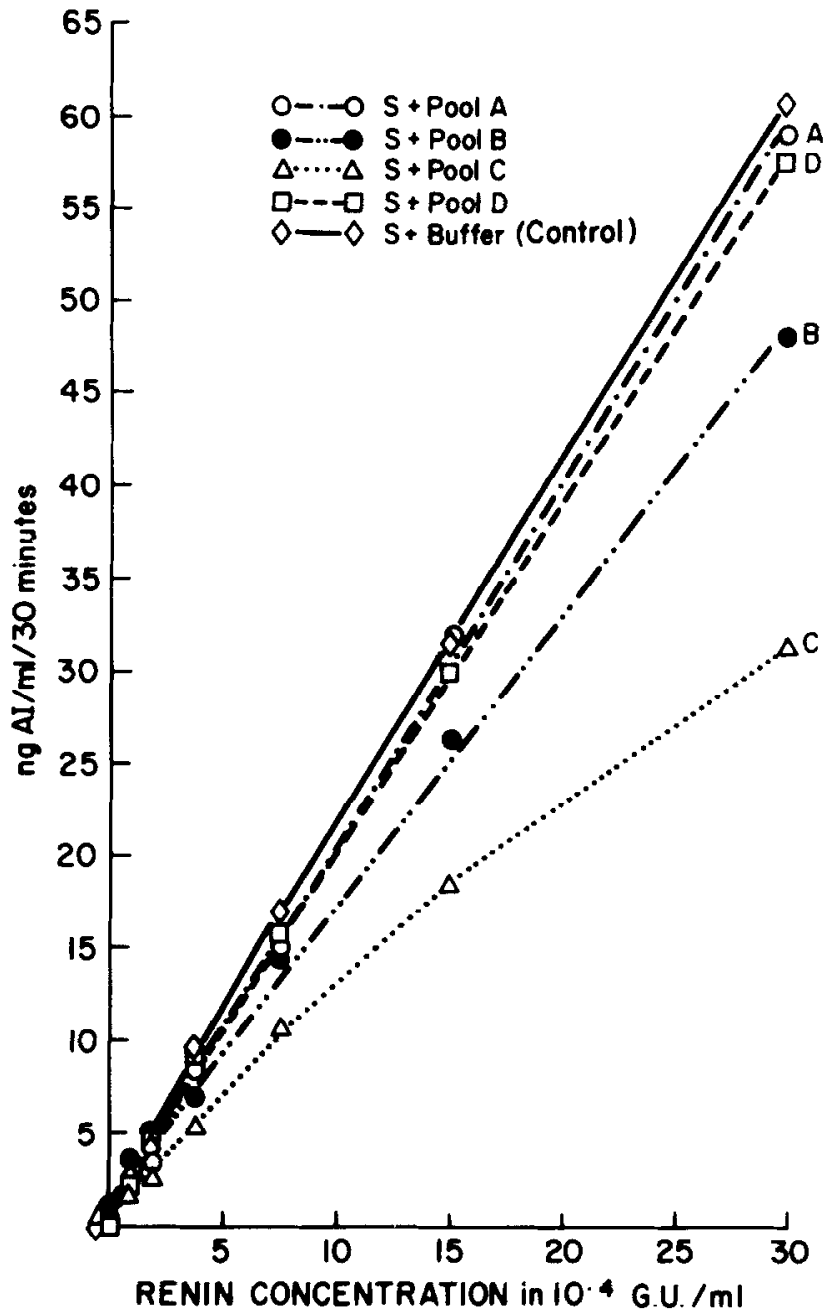

Table 3. Enzyme Inhibitory and Angiotensinase Activities of Pooled Fractions

\begin{tabular}{|c|c|c|c|c|c|c|c|c|}
\hline & \multicolumn{4}{|c|}{ Enzyme Inhibitory Activity ${ }^{*}$} & \multicolumn{4}{|c|}{ Angiotensinase Activity ${ }^{\circ}$} \\
\hline & $n$ & $\begin{array}{c}\text { Al } \\
\text { Generation } \\
\text { Ratef }\end{array}$ & $\begin{array}{c}\% \\
\text { Inhibition }\end{array}$ & $\rho$ & $n$ & $\mathrm{ng} A \mathrm{l} / \mathrm{ml}$ & $\begin{array}{c}\% \\
\text { Degradation }\end{array}$ & $\rho$ \\
\hline Control & 10 & $4.41 \pm 0.13$ & - & - & 10 & $7.3 \pm 0.63$ & - & - \\
\hline Pool B (DEAE) & 9 & $3.53=0.10$ & 20.0 & 0.0002 & 10 & $4.7 \pm 0.09$ & 36 & 0.001 \\
\hline Pool C (DEAE) & 10 & $2.55 \pm 0.09$ & 42.2 & 0.000001 & 5 & $5.6 \pm 0.38$ & 24 & 0.048 \\
\hline Control & 9 & $6.25 \pm 0.08$ & - & - & 11 & $10.5 \pm 0.51$ & - & - \\
\hline Pool $C_{1}$ (G-200) & 9 & $6.07 \pm 0.14$ & 2.8 & 0.29 & 5 & $11.7 \pm 0.95$ & - & 0.25 \\
\hline Pool $C_{2}$ (G-200) & $\mathbf{9}$ & $5.17 \pm 0.17$ & 17.3 & 0.0001 & 12 & $11.1 \neq 0.77$ & - & 0.54 \\
\hline
\end{tabular}

$n=$ number of replicate samples run

$p=$ statistical significance level.

"Assays were run as described in Methods, section 2. Low-renin-activity plasma was used as a substrate source. In the assay for enzyme inhibitory activity, renin concentrations were the same as those used in the experiments shown in Fig. 5.

t Rate measured as nanograms Al per hour per $10^{-4}$ Goldblatt units of renin (mean \pm SEM). 
enzymatic action of renin. Only pools $B$ and $C$ appeared to inhibit the generation of angiotensin I (Fig. 5 and Table 3). The apparent inhibitory activity of pool B was found to be $20 \%$, while that of pool C was $42 \%$. Studies were performed to determine whether this apparent decrease in $\mathrm{AI}$ generation might be due to angiotensinase activity. As shown in Table 3, pools B and C degraded $36 \%$ and $24 \%$ of added AI, respectively. Thus pool C had a greater ratio of apparent inhibitory:angiotensinase activity than $\mathrm{B}$.

Therefore pool C was further purified by Sephadex G-200 column chromatography. Renin-antirenin inhibitory activity was found in the second of two protein peaks (Fig. 6). The fractions from each peak were pooled and concentrated 15fold (pools $\mathrm{C}_{1}$ and $\mathrm{C}_{2}$ ). These pools were dialyzed against 0.1-M acetate buffer (pH 5.5) and tested for angiotensinase activity to AI and for inhibitory activity to the enzymatic action of renin as before. Results of these studies are also shown in Table 3. Neither pool exhibited any angiotensinase activity. However, pool $\mathrm{C}_{2}$ was found to contain significant inhibitory activity to the enzymatic action of renin. This pool was further tested for enzymatic inhibition, using plasmas of both normal subjects (normal-renin-activity group) and patients with low renin hypertension and primary aldosteronism (low-renin-activity group) as a substrate

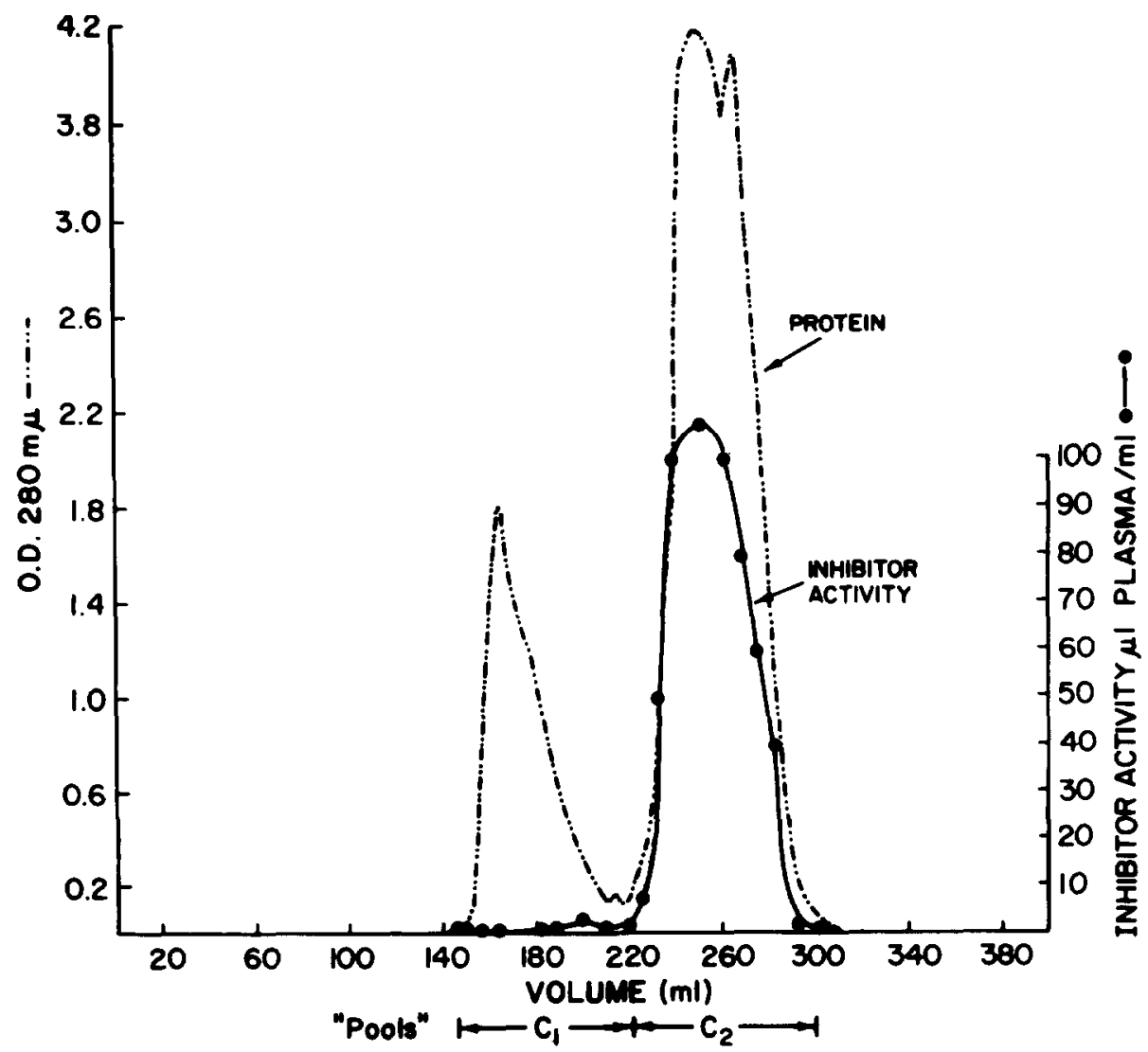

Fig. 6. Profile of renin-antirenin inhibitory activity following Sephadex G-200 column chromatography of fraction $\mathbf{C}$. 
Table 4. Enzymatic Inhibitory Activity of Pool $\mathrm{C}_{2}$ Tested Against Individual

Plasmas of Normal People and Patients with Low-Renin Hypertension (LRH) and Primary Aldosteronism (1 $\left.{ }^{\circ} \mathrm{A}\right)$

\begin{tabular}{lllc}
\hline \multicolumn{1}{c}{ Subject } & $\begin{array}{c}\text { Condition } \\
\text { and PRA }\end{array}$ & N & $\begin{array}{c}\text { \% Inhibitory } \\
\text { Activity }\end{array}$ \\
\hline 284 & Normal (7.5) & 5 & 3.3 \\
301 & Normal (12.5) & 5 & 16.0 \\
305 & Normal (6.0) & 5 & -6.3 \\
313 & Normal (2.2) & 5 & 23.0 \\
352 & Normal (16.4) & 5 & 18.5 \\
382 & Normal (1.9) & 5 & 5.8 \\
398 & Normal (7.0) & 5 & 9.2 \\
Mean \pm SEM & & & $9.9 \pm 3.8$ \\
\hline 1299 & LRH (1.8) & 5 & 21.4 \\
1340 & LRH (2.0) & 5 & 25.0 \\
1340 & LRH (2.0) & 5 & 19.1 \\
1757 & LRH (2.0) & 5 & 13.4 \\
2060 & $1^{\circ}$ A (0.29) & 5 & 19.0 \\
2061 & $1^{\circ}$ A (0.37) & 5 & 21.0 \\
2063 & $1^{\circ}$ A (0.69) & 5 & 27.0 \\
Mean \pm SEM & & & $20.8 \pm 1.67$ \\
\hline Significance level between the above means & & 0.022 \\
\hline
\end{tabular}

- Condition of subject (i.e., normal, LRH, $1^{\circ} \mathrm{A}$ ) and PRA of the subject's plasma, which was used as a substrate source in that experiment. PRAs (shown in parentheses) were determined by radioimmunoas;say for $\mathrm{Al}$ and are expressed as $\mathrm{ng} / \mathrm{ml} / \mathrm{hr}$. $^{14}$

tEach control and experimental assay was run in quintuplicate.

\$Mean percentage inhibitory activity as compared to controls. Assays were run as described in Methods, section 2: $10 \quad$ I of human renin $\left(1.8 \times 10^{-2} \mathrm{G} . \mathrm{U} . / \mathrm{ml}\right)$ was added to bring the final renin concentration to $1.5 \times 10^{-3} \mathrm{G} . \mathrm{U} . / \mathrm{ml}$.

source (Table 4). In vitro inhibitory activity was observed against all but one normal plasma, the mean inhibition being $9.9 \%$ from control. When low-reninactivity plasmas were used as a substrate source, mean inhibitory activity of pool $\mathrm{C}_{2}$ was $20.8 \%$ from control. The difference between these means $(9.9$ vs. 20.8$)$ was significant at the 0.05 level.

\section{DISCUSSION}

Plasma renin activity is a measure of the in vitro reaction between plasma renin and its substrate at $37^{\circ} \mathrm{C}$. This reaction rate is affected by factors in plasma besides renin, probably renin inhibitors and/or renin substrate. ${ }^{1-7}$ These facts raise the question of the capability of PRA assays to measure plasma renin concentration (PRC). It was for this reason that we attempted to develop a radioimmunoassay for renin. There are indirect methods for measuring renin, one of which utilizes heterologous substrate added in great excess to the plasma sample before generation of AI. Alternatively, the in vitro assay for PRA can be modified by the addition of purified human renin as an internal standard. ${ }^{15}$ In this way it is possible to reliably measure PRC. Employing this latter method we have found the correlation between PRA and PRC of 22 normotensive subjects to be highly significant, $r=+0.728$ (unpublished data). In the present report we have employed a renin radioimmunoassay method to measure PRC, which we refer to 
as immunoreactive renin (IRR). The correlation coefficients $(r)$ for each of the 20 assays in which PRA and IRR were measured ranged from +0.020 to +0.878 (Table 1). Though always positive, only 7 of 20 had correlations significant at the $5 \%$ level, and thus most correlations fall short of the theoretical norm referred to above. In the 7 assays where $r$ was significant, the average PRAs tended to be high (e.g., assays 25,34 , and 117). Although these results, taken as a whole, indicate that the ${ }^{131}$ I-renin-antirenin system we have developed is capable of detecting renin in human plasma, they also indicate that certain discrepancies exist when comparing renin concentration measured by the radioimmunoassay (IRR) to that measured by the indirect method described above (PRC).

In this regard, the results illustrated in Fig. 1 may explain this discrepancy. Here we have evidence that another factor besides renin affects the radioimmunoassay system, since low-renin-activity plasma (and plasma of anephric individuals) is shown to inhibit binding of ${ }^{13}$ I-renin to antirenin. The presence of this other factor is supported by the results shown in Table 2, where, employing nonradioactive renin and using the technique of complement fixation, we observed interference by serum with the renin-antirenin reaction. This phenomenon does not appear to be caused by incubation damage to renin (Fig. 2). Rather, it appears to be caused by a reaction of the radioimmunoassay reagents with a specific protein or proteins, as the results described in Figs. 3 and 4 suggest. The tracing in Fig. 3 indicates that the renin-antirenin inhibitor of plasma has the same molecular size as renin substrate. This correlation has been repeatedly demonstrated in individual plasma samples fractionated by Sephadex G-200 column chromatography. Were it not for the study employing DEAE cellulose chromatography of the same plasma, one might conclude that the renin-antirenin inhibitor is renin substrate. From the study illustrated in Fig. 4, however, it is clear that the reninantirenin inhibitor and renin substrate overlap but are not identical. We see, for example, that the major inhibitory fraction elutes slightly ahead of the substrate fractions. A minor inhibitory peak then corresponds with the appearance of the substrate fractions, and while fractions containing substrate activity continue to elute, inhibitory activity has ceased. Thus there exists the real possibility that the renin-antirenin inhibitor may be made up of certain renin-substrate fractions as well as other fractions with the same molecular size as renin substrate, but not containing substrate activity.

Our suspicion that the renin-antirenin inhibitor might also possess inhibitory activity against the enzymatic action of renin prompted us to investigate this possibility. Pool C obtained from DEAE cellulose column chromatography (Fig. 4) and pool $\mathrm{C}_{2}$ obtained from Sephadex G-200 column chromatography of C (Fig. 6) were thus found to possess both renin-antirenin inhibitory activity and inhibitory activity against the enzymatic action of renin (Tables 3 and 4). When pool $C_{2}$ and renin, the latter added in excess, were added to low-PRA plasma serving as a substrate source, a $17.3 \%$ inhibition (from control) of AI generation resulted, $p<0.0001$ (Table 3 ). The experiments illustrated in Table 4 were conducted to study the inhibitory effect of pool $C_{2}$ when several other plasmas were used as a substrate source. We chose the plasma of 7 normal people and the plasma of 7 people with low PRA for this experiment. As the results in Table 4 show, pool $\mathrm{C}_{2}$ inhibitor produced significantly more inhibition when low-PRA plasma was used as a substrate source than when normal-PRA plasma was used. 
A problem, of course, is how to interpret these results. Skeggs has proposed that hog-renin substrate is an $\alpha_{2}$-globulin to which is attached a 14 amino acid peptide (tetradecapeptide). Renin reacts with the tetradecapeptide moiety, splitting off the 10 amino acid angiotensin $I .{ }^{16}$ From our unpublished studies we know the molecular weight of human renin substrate to be about 75,000 . Since angiotensin I has a molecular weight of 1300 , we can conclude that the reaction between renin and its substrate is as follows:

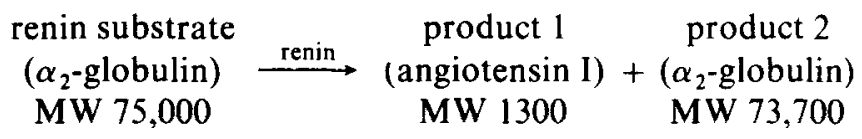

We can also conclude that in the relative absence of renin, little of product 2 is being formed. Thus a plasma may have varying ratios of renin substrate to product 2. On the basis of this formulation, and from the results seen in Fig. 3, we can speculate that the renin-antirenin inhibitor could be either renin substrate (MW 75,000) and/or product 2 (MW 73,700), since both of these have essentially the same size and should migrate together on Sephadex G-200. On the other hand, renin substrate and product 2 (which has no substrate activity) could easily possess a difference in charge accounting for the results seen with anion-exchange chromatography (Fig. 4), where renin-antirenin inhibitor and substrate are separate but overlap. It would also make sense that renin substrate or product 2 could interact stereochemically with renin and thus could interfere with the renin-antirenin reaction. In addition, product 2 could interfere with renin's capacity to react with its own substrate and may qualify as inhibitor of enzymatic activity. These concepts need to be tested. Nevertheless, they are consistent with the various observations that we and others have made. For example, anephric plasma has been shown to produce less inhibition to renin added in vivo or in vitro. ${ }^{17}$ This presumably could be due in part to the relative deficiency of product 2. In our studies anephric plasma has been found to contain renin-antirenin inhibitory activity. This could be explained by the presence of renin substrate in the absence of product 2 . In our studies we have shown that inhibitor (pool $\mathrm{C}_{2}$ ) has more activity when added to low-PRA than when added to normal-PRA plasma. One possible interpretation of these data is that there is a greater quantity of endogenous inhibitor in normal-PRA plasmas and that addition of (pool $\mathrm{C}_{2}$ ) inhibitor to them might have less effect, if the inhibitory response is not linear. Of particular relevance to this thesis is our recent observation that reactivity of plasma (defined as the generation rate of angiotensin I on addition of renin, and used here as an index of inhibitory capacity of plasma) was inversely related to the plasma renin concentration in a study of 88 plasma samples. ${ }^{18}$ Further studies of course are needed, especially those dealing with the in vitro generation and subsequent purification of product 2 from renin substrate.

The presence of an inhibitor to renin in plasma has previously been reported, ${ }^{17}$ and the kidney has been assumed to be a possible source. ${ }^{19-22}$ This inhibitor has been identified as a phospholipid. Recently a great deal of interest has been created by the observation that different plasmas generate AI unequally 
following the addition of exogenous renin, an observation first made by Boucher et al. in 1964, as well as by Pickens et al. in 1965., It is still not possible, however, based on our own data or that of others, to state with any degree of certainty that a physiologic renin inhibitor does exist, although certain lines of investigation are suggested. However, our studies clearly describe an interaction between renin and a specific serum factor or factors that makes a radioimmunoassay for renin difficult. It is probably fair to say that much more work will be necessary before success in this area can be realized.

\section{ACKNOWLEDGMENT}

The authors are grateful to Dr. Prasanta Datta of the Department of Biological Chemistry, University of Michigan Medical School, for help and criticism given during the course of this study and to Dr. Lee Bartholomew for performing complement-fixation studies. The authors are also grateful to Gregory Holzwarth for helpful criticism in the writing of this paper.

\section{REFERENCES}

1. Boucher R, Veyrat $\mathbf{R}$, d'Champlain J, et al: New procedures for measurements of human plasma angiotensin and renin activity levels. Can Med Assoc J 90:194, 1964

2. Pickens PT, Bumpus FM, Lloyd AM, et al: Measurement of renin activity in human plasma. Circ Res 17:438, 1965

3. Haas E, Gould AB, Goldblatt H: Estimation of endogenous renin in human blood. Lancet 1:657, 1968

4. Brown JJ, Davies DL, Lever AF, et al: The estimation of renin in human plasma. Biochem $\mathbf{J}$ 93:594, 1964

5. Helmer OM, Judson WE: The quantitative determination of renin in the plasma of patients with arterial hypertension. Circulation 27:1050, 1963

6. Gould AB, Skeggs LT, Kahn JR: Measurement of renin and substrate concentration in human serum. Lab Invest 15:1802, 1966

7. Skinner SL: Improved assay methods for renin "concentration" and "activity" in human plasma: Methods using selective denaturation of renin substrate. Circ Res 20:391, 1967

8. Lucas $C P$, Fukuchi $S$, Conn JW, et al: Purification of human renin. J Lab Clin Med $76: 689,1970$

9. Hunter WM, Greenwood FC: Preparation of iodine-131-labelled human growth hormone of high specific activity. Nature 194:495, 1962

10. McFarlane AS: Efficient trace-labelling of proteins with iodine. Nature 182:53, 1958

11. Morgan CR, Lazarow A: Immunoassay of insulin using a two antibody system. Proc Soc Exp Biol Med 110:29, 1962

12. Cohen EL, Conn JW, Rovner DR: Postural augmentation of plasma renin activity and aldosterone excretion in normal people. J Clin Invest 46:418, 1967

13. Sever JL: Application of a micro-technique to viral serological studies. J Immunol 88:32, 1962

14. Cohen EL, Grim CE, Conn JW, et al: Accurate and rapid measurement of plasma renin activity by radioimmunoassay. Results in normal and hypertensive people. J Lab Clin Med 77:1025, 1971

15. Cohen EL, Conn JW, Lucas CP, et al: in: Hypertension 1972. Berlin, Springer-Verlag, 1972, p 569

16. Skeggs LT, Lentz KE, Hochstrasser H, et al: Chemistry of renin substrate. Can Med Assoc J 90: 185, 1964

17. Blaquier P, Hoobler SW, Schroeder J, et al: Effect of bilateral nephrectomy on pressor response to renin. Am J Physiol 203:339, 1962

18. Lucas CP, Holzwarth G, Ocobock R, et al: Renin: Activity, reactivity and concentration in a population survey. Relationship to blood pressure. Angiology (Dec. 1974)

19. Ostrovsky D, Sen S, Smeby RR, et al Chemical assay of phospholipid renin preinhibitor in canine and human blood. Circ Res 21:497, 1967

20. Sen S, Smeby RR, Bumpus FM: Isolation of a phospholipid renin inhibitor from kidney. Biochemistry 6:1572, 1967

21. Regoli D, Brunner H, Gross F: Untersuchungen uber den mechanismus der wirkungverstarkung von renin nach nephrektomie. Helv Physiol Pharmacol Acta 19:C101, 1961

22. Sokabe H, Shibayama F, Mizogami S, et al: Cardiovascular reactivity after bilateral nephrectomy in rats. Jap Heart J 6:233, 1965 